
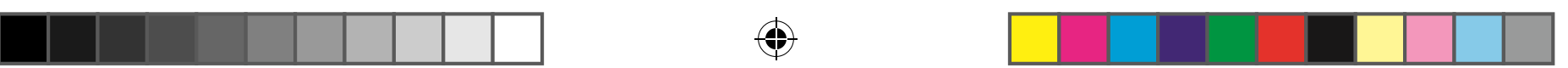

\title{
CONVIVÊNCIA COM O SEMIÁRIDO E O USO DAS TECNOLOGIAS SOCIAIS AGROECOLÓGICAS NO SERTÃO NORDESTINO
}

Edir Vilmar Henig ${ }^{1}$

\section{RESUMO}

As Tecnologias Sociais surgem como resposta aos anseios dos agricultores empobrecidos que necessitam de uma nova possibilidade ao seu pertencimento no meio rural. Estas garantem aos mesmos uma participação produtiva com poucos recursos e com respeito ao ambiente, inibindo desta forma a exclusão social promovida pela hegemonia do agronegócio. A proposta das Tecnologias Sociais é impulsionar a transformação social através de produtos, métodos e técnicas produtivas que tenham por finalidade a promoção social, econômica e ambiental dos envolvidos no cultivo agrícola. Associadas à agroecologia estas tecnologias auxiliam a produção sustentável, com a potencialização do uso dos recursos naturais do semiárido e minimiza o uso de produtos agroquímicos. O objetivo deste trabalho é verificar quais são as principais tecnologias sociais utilizadas no semiárido nordestino brasileiro, a fim de promover o debate em torno da promoção

1 Doutor em Território, Risco e Políticas Públicas pela Universidade de Coimbra. Mestre em Política Social e Graduado em Administração pela Universidade Federal de Mato Grosso. Professor da Universidade Federal de Mato Grosso. 
destes métodos produtivos com a potencialização de políticas públicas que beneficiem estes trabalhadores e respeitando o saber popular. Para isso, foi realizada uma revisão teórica acerca de conceitos de agroecologia e de tecnologia social bem como a contextualização geográfica da Região Nordeste do Brasil, elencando suas potencialidades econômicas e sociais.

Palavras-chave: Agroecologia. Tecnologia Social. Semiárido. Políticas Públicas. Trabalho.

\section{INTRODUÇÃO}

A agricultura sempre esteve presente no modelo econômico adotado pelo Brasil desde sua colonização. Um modelo hegemônico que estabeleceu os limites da ruralidade brasileira, imposto através da violência, da expropriação, da grilagem e do conluio com o Estado que esteve sempre a serviço dos grandes latifúndios.

Este modelo concentrador deu origem ao agronegócio que vivenciamos hoje. Com auxílio da tecnologia de ponta, este modelo continua privilegiando a poucos e excluindo os muitos, pequenos produtores. Nesta perspectiva, as tecnologias sociais surgem ou se aperfeiçoam com o objetivo de fortalecer a produtividade do agricultor de base familiar, dando a eles autonomia e condições de produzir.

As tecnologias sociais associadas com a agroecologia possibilitam ao agricultor produzir alimentos saudáveis sem a utilização de insumos químicos, barateando o custo de produção e chegando ao mercado com valor agregado, pois os produtos oriundos da agroecologia possuem qualidade superior aos da agricultura convencional.

Outro fator que deve se destacar é a sustentabilidade da produção. A agroecologia tem por princípio a utilização dos recursos naturais de forma sustentável, respeitando os limites da natureza. Este modelo produtivo é baseado em métodos e técnicas produtivas que respeitam as tradições e os saberes populares e a convivência com os recursos naturais. 
No contexto nordestino a agroecologia é uma ferramenta importante no combate à pobreza rural, além de possibilitar que o agricultor conviva com a realidade do sertão de forma mais amena. As tecnologias sociais se associam à agroecologia e garantem a resistência aos grandes períodos de estiagem com baixo investimento, aperfeiçoando técnicas há muito utilizadas para garantir a reprodução social dos trabalhadores rurais do semiárido.

O objetivo deste trabalho é verificar quais são as principais tecnologias sociais utilizadas no semiárido nordestino brasileiro, a fim de promover o debate em torno da promoção destes métodos produtivos com a potencialização de políticas públicas que beneficiem estes trabalhadores e respeitando o saber popular. Para isso, foi realizada uma revisão teórica acerca de conceitos de agroecologia e de tecnologia social, bem como a contextualização geográfica da Região Nordeste do Brasil, elencando suas potencialidades econômicos e sociais, para através destes pontos, estabelecer as principais técnicas utilizadas pelos agricultores, demonstrando de que forma podem auxiliar na produção e manutenção destes trabalhadores naquele espaço.

\section{AS TECNOLOGIAS SOCIAIS E SUAS RELAÇÕES DE SABERES COM A AGROECOLOGIA}

A construção de uma sociedade ambientalmente sustentável, economicamente equilibrada e socialmente justa, começa pela integração interdisciplinar do conhecimento, pois é através do diálogo dos diversos fragmentos científicos que novas perspectivas teóricas, metodológicas e práticas que se possibilita a evolução para uma nova sociedade possível.

Este saber surge da necessidade de resposta para as diferentes mazelas sociais que - devido desenvolvimento do capitalismo que privilegia o desenvolvimento econômico a curto prazo em favor da lógica do mercado - relega a distribuição de renda, a desigualdade social e proteção do meio ambiente a segundo plano, ou ainda, deixa que a regulação se dê através da "mão invisível do mercado". 
Os saberes tradicionais excedem as ciências convencionais, que são constituídas de especializações formadas e pelas disciplinas convencionais (antropologia, ecologia, economia, sociologia, física, agronomia, etc.) e que auxiliam diretamente na produção de soluções locais, baseadas nas necessidades de cada comunidade.

A reorganização da pesquisa, a reelaboração dos conteúdos curriculares e dos métodos pedagógicos, nas perspectivas do desenvolvimento sustentável, implicam a construção de um novo saber ambiental e sua internacionalização nos paradigmas científicos e nas práticas docentes que prevalecem. Este processo se defronta com obstáculos que provêm da institucionalização dos paradigmas dominantes, legitimados e arraigados nos critérios de valorização do conhecimento no meio acadêmico e na sociedade em seu conjunto. (LEFF, 2013, p. 203)

A institucionalização do saber e o determinismo que o privilegia apenas a ciência acadêmica e desprestigia os conhecimentos tradicionais se apresentam como barreira para a superação de problemas ambientais e refletem diretamente no desenvolvimento da sociedade.

A cultura dominante do saber é colocada por Gramsci (2011, p. 202) como um erro intelectual, pois segundo o autor "saber sem compreender e, principalmente, sem sentir e estar apaixonado", ou seja, sem que estes elementos estejam diretamente ligados, transforma o saber em algo apenas burocratizado, formal, impositivo, mecânico: "os intelectuais se tornam uma casta ou um sacerdócio". Mas quando a relação se dá graças às relações orgânicas - na qual os sentimentos de respeito ao conhecimento do outro - então temos neste momento o saber de fato, representativo e de troca, criando uma força social capaz de romper com as lógicas dominantes.

A reprodução da ciência moderna da forma como vem sendo feita é apenas um método de manter os status hegemônico do sistema capitalista, no qual a ciência para além de colaborar na solução de problemas sociais é apenas mais uma mercadoria que está posta no mercado para quem pode pagar por ela. O saber tradicional é uma 
alternativa de desenvolvimento de tecnologias sociais que ofereçam às comunidades resultados precisos a baixo custo.

Nesta perspectiva, utilizamos o pensamento de Santos (2010, p. 143) referente a "ecologia de saberes", que nada mais é do que "um conjunto de epistemologias que partem da possibilidade da diversidade e da globalização contra hegemônica e pretendem contribuir para as credibilizar e fortalecer".

Podemos afirmar ser uma ecologia porque está alicerçada na apresentação de diversos conhecimentos heterogêneos, sendo assim plurais, e que incluem a ciência moderna. Garante ainda interação entre estes saberes sem colocar em risco a autonomia de cada um deles. Sendo assim, "a ecologia de saberes baseia-se na ideia de que o conhecimento é interconhecimento" (SANTOS, 2010, p. 44-45).

Para além de desenvolver novas pesquisas é necessário garantir que os saberes já existentes sejam preservados para que as futuras gerações possam gozar destes conhecimentos, sem que a ciência moderna o sucumba. A aplicação de tecnologias sociais, sejam elas novas ou antigas, devem garantir que as particularidades de cada comunidade sejam preservadas, sem que estas percam sua identidade e relação com a natureza.

A transferência de tecnologias específicas para outros lugares e contextos pode fracassar, caso os solos, os implementos e a organização social sejam diferentes. É por isso que agroecólogos não se prendem em tecnologias específicas, mas sim nos princípios utilizados pelos agricultores tradicionais para atender às exigências ambientais de seus sistemas de produção. (ALTIERI, 2012, p. 165)

Para as populações rurais a força do conhecimento não está firmada apenas na observação aguçada, mas diretamente na aprendizagem, principalmente àquela que é transferida de geração para geração, e pelo empirismo. A experimentação diretamente ligada à seleção de sementes, por exemplo, não se limita apenas a isso, pode também estar direcionada em técnicas de produção biológicas e socioeconômi- 
cas. Segundo Richard, "habilidades locais podem ser mobilizadas por meio de abordagens participativas de desenvolvimento, combinando o saber local com o conhecimento e as competências dos agentes externos na concepção e difusão de técnicas agrícolas apropriadas" (RICHARDS, 1985, p. 89).

Foi nesta perspectiva que pensadores progressistas mobilizaram o povo indiano no final do século XIX com a finalidade de estabelecer profundas reformas naquela sociedade através de tecnologias tradicionais. A ideia partia da reinvenção de tecnologias tradicionais já existentes e do desenvolvimento de novas, sendo que este movimento era a principal ferramenta de luta contra o imperialismo britânico.

O que é bom para uma nação com uma determinada condição não é necessariamente bom para outra numa situação diferente. A comida de um homem é muitas vezes o veneno de outro (...) A mecanização é boa quando as mãos são poucas para o trabalho que se pretende concretizar. É má quando há mais mãos do que as necessárias para o trabalho, que é o que acontece na Índia." (PYARELAL, 1959, p. 150)

Gandhi pensou a roda de fiar como instrumento simbólico da libertação e como ferramenta apropriada para o desenvolvimento da Índia. Direcionou sua crítica ao modelo de industrialização que se pautava no ocidente e que promovia a pobreza, expropriação dos cidadãos, exclusão e destruição dos recursos que subsidiavam a sociedade indiana.

Foi para recuperar os modos de subsistência na Índia que Gandhi pensou na roda de fia como símbolo de libertação e como ferramenta para o desenvolvimento. As fábricas movidas a energia eram o modelo de desenvolvimento naquele período de industrialização inicial. Todavia, a fome das fábricas por matérias-primas e mercados foi a razão para uma nova pobreza, criada pela destruição dos modos de subsistências, fosse por desviarem terra e biomassa da subsistência local para a fábrica, fosse por marginalizarem a produção local através do mercado. (SHIVA, 2015, p. 240) 
A roda de fiar passou a simbolizar a conservação de recursos através de tecnologias baratas, que não agrediam o meio ambiente, e que promoviam emprego e renda as pessoas, garantindo subsistência às mesmas e desta forma passavam a ser detentoras de alguns dos meios de produção, o que lhes dava controle sobre suas vidas.

A autonomia das pessoas garantia as individualidades no processo produtivo e já não eram mais consideradas peças de reposição das fábricas inglesas. A dependência econômica e política que eram características da industrialização colonialista inglesa deram lugar a descentralização do processo produtivo, geração de renda e conservação dos recursos.

[...] Gandhi dedicou-se a construir programas, visando a popularização da fiação manual realizada em uma roda de fiar reconhecida como o primeiro equipamento tecnologicamente apropriado, a Charkha, como forma de lutar contra a injustiça social e o sistema de castas que a perpetuava na Índia. Isso despertou a consciência política de milhões de habitantes do povo e da renovação da indústria nativa hindu, o que pode ser avaliado pela significativa frase pele ele cunhada: "Produção pelas massas, não produção em massa". (DAGNINO, BRANDÃO e NOVAES, 2016, p. 5)

A luta de Gandhi em popularizar e disseminar as tecnologias tradicionais se espalhou pelo mundo. $\mathrm{O}$ fato de garantir emprego e renda com baixa aplicação de recursos, levando em consideração o saber de cada população, simplicidade e respeito aos recursos naturais, tornou este modelo tecnológico facilmente adaptável à realidade de países pobres, devolvendo a estas populações sua subsistência.

Já no Brasil, este processo surge nos anos de 1970 ainda com a nomenclatura de tecnologia alternativa. Teve relação muito próxima com as universidades, institutos de pesquisas e as comunidades. Em 2001 cria-se prêmio juntamente com a Fundação Banco do Brasil com o objetivo de alavancar este modelo tecnológico.

Já em 2005 é criada a Rede de Tecnologias Sociais, que tem por objetivo a inclusão social, geração de emprego e renda, promoção 
do desenvolvimento local e sustentável. Esta rede visava a agregar diferentes instituições que trabalhassem, pesquisassem ou tivessem interesses comuns no desenvolvimento da sociedade através de tecnologias populares.

Segundo, Seixas et al. (2015, p. 2680), "para a RTS, Tecnologia Social consiste nos produtos, técnicas ou metodologias reaplicáveis, desenvolvidas por meio da interação com a comunidade e que representem efetivas soluções de transformação social", neste sentido é importante destacar que a cooperação entre pesquisadores acadêmicos que desenvolvem métodos, técnicas e práticas científicas, e os saberes populares, são responsáveis pela solução rápida, ecológica, econômica e com capacidade de transformação social de problemas simples do cotidiano das pessoas que vivem em comunidade.

Um dos vários objetivos da tecnologia social repousa na capacidade emancipatória dos sujeitos envolvidos, sendo estes os idealizadores, produtores e usuários destas ferramentas.

[...] a tecnologia social implica na construção de solução de modo coletivo pelos que irão se beneficiar dessas soluções e que atuam com autonomia, ou seja, não são apenas usuários de soluções importadas ou produzidas por equipes especialistas, a exemplo de muitas propostas das diferentes correntes da tecnologia apropriada. (RODRIGUES, IWATA, BARBIERI. 2005, p. 5)

É importante destacar que a produção de conhecimento das tecnologias sociais é específica para uma comunidade, região ou espaço geograficamente referenciado, como destaca Dagnino et al (2004, p. 56-57) quando diz que 'a inovação não pode ser pensada em algo jeito num lugar e aplicado em outro, mas como um processo desenvolvido no lugar onde essa tecnologia vai ser utilizada, pelos atores que irão utilizá-las". Isso não anula a possibilidade e viabilidade de que uma inovação possa ser utilizada em outras regiões, por outros sujeitos, mas que este usuário pode adaptar para a sua realidade.

Um exemplo que podemos utilizar é a troca de informação realizada pelo governo do Ceará no âmbito do combate à seca e a desertifica- 
ção e o governo de Israel, onde se foi buscar no país do Oriente Médio métodos e técnicas de irrigação que pudessem ser utilizados no Semiárido Cearense. A irrigação por gotejamento vem sendo implementada e testada com a finalidade de promover a agricultura e o desenvolvimento econômico e social no interior do Estado.

Inicialmente é necessário nos situarmos na discussão das tecnologias sociais, a partir do modelo de produção capitalista, comandado pelo capital financeiro e por grandes multinacionais, e que se servem da produção de tecnologia não apenas para transformar a vida das pessoas, mas antes como ferramenta de geração de lucro.

Nossa visão é a de que a ciência reforça "sua" sociedade e tende a inibir a mudança social. Ou seja, a ciência e a tecnologia produzidas sob a égide da formação social capitalista tendem a inibir uma mudança que contrarie suas regras de funcionamento, que debilite a acumulação de capital, que aponte para uma forma de organização do processo de trabalho e da vida em sociedade diferente. (DAGNINO, 2004, p. 13).

Seguindo este raciocínio, é difícil que haja um desenvolvimento pleno das tecnologias sociais se o capital estiver envolvido diretamente, é por isso que existe a necessidade que os desenvolvimentos destes métodos estejam diretamente ligados com as Universidades, ONGs e comunidade, se isentando de financiamento privado que teria o objetivo de revender estas patentes e lucrar com este produto.

As perspectivas de uma Tecnologia Social deve ter comprometimento com a transformação social, proporcionar as comunidades o espaço de descoberta e ampliar as inovações já existentes, sustentabilidade socioambiental e econômica, inovação, organização e sistematização do conhecimento, deve ainda: garantir o acesso e a apropriação do conhecimento, criar ferramentas pedagógicas que efetivem a troca de saberes e a participação social que assegurem aos envolvidos a cidadania ampliada, no seu sentido mais restrito.

É contraditório se falar em cidadania em tempos de capitalismo avançado e de ampliação do neoliberalismo no Brasil e no mundo, e 
neste sentido Coutinho ressalta a dialética entre cidadania $x$ capitalismo, dizendo que "não hesitaria em dizer que a ampliação da cidadania - esse processo progressivo e permanente de construção dos direitos democráticos que caracteriza a modernidade - termina por se chocar com a lógica do capital" (COUTINHO, 2005, p. 15).

Mais do que a capacidade de implementar soluções para determinados problemas, podem ser vistas como métodos e técnicas que permitam impulsionar processos de empoderamento das representações coletivas da cidadania para habilitá-las a disputar, nos espaços públicos, as alternativas de desenvolvimento que se originam das experiências inovadoras e que se orientam pela defesa dos interesses das maiorias e pela distribuição de renda. (BAVA, 2004, p. 116).

É a partir deste ponto que começamos a conceituar a Tecnologia Social, nas bases de pesquisadores brasileiros e estrangeiros, amparados também pelo que diz a Rede de Tecnologia Social, já apontada acima, e também o Instituto de Tecnologia Social.

Amílcar Herrera - pesquisador argentino, que iniciou o debate em torno das Tecnologias Sociais como instrumento de diminuição das desigualdades sociais nos países periféricos - destaca que a solução para o enfrentamento das desigualdades é através do desenvolvimento das ciências e tecnologias (1970, p. 36). Muito embora, para este autor, a participação socia é importante apenas para garantir a efetivação da solução produzida pela tecnologia, sendo de cabo do pesquisador o desenvolvimento do processo.

O trabalho com o termo TS (Tecnologia Social) nasce, assim, na história do ITS [...], como o esforço do reconhecimento do tipo de produção e atuação específica das ONGs, que de modo geral revela uma relação diferenciada entre produção e a aplicação de conhecimento. [...] É um modo de legitimar as ONGs junto ao sistema de CT\&I (permitindo que tenham acesso a recursos destinados à produção científica, tecnológica e inovativa do país) e também organizar e disseminar experiências que contenham elementos de TS. [...] A reflexão e a construção 
do conceito de TS devem ser capazes de melhorar práticas sociais e de contribuir para que novos significados para a produção de conhecimento sejam contribuídos, aproximando os problemas sociais de solução e ampliando os limites da cidadania. (ITS, 2004, p. 123)

Quando se discute a tecnologia social, é importante levar em conta o caráter crítico que envolve sua conceituação. Em um país como o Brasil onde a realidade social está mergulhada em desigualdades existe a necessidade urgente de políticas públicas voltadas para o desenvolvimento desta forma de ciência, que garanta o desenvolvimento de comunidades há muito colocadas à margem da sociedade, principalmente para produtores rurais em situação de pobreza, coletores de castanhas, comunidades ribeirinhas, quilombolas, indígenas, entre outros.

[...] as tecnologias sociais são tratadas pelo campo hegemônico e no âmbito da ciência e tecnologia como iniciativas residuais, que atenuam ou reduzem problemas que podem ser enfrentados por políticas de caráter focalizado e compensatório. Ou ainda alguns intelectuais do campo social, consideram as tecnologias sociais como sendo um instrumento neoliberal, e, portanto, um instrumento de manobra hegemônico. Ao contrário disto, os atores sociais envolvidos com a implementação e o desenvolvimento de tecnologias sociais no Brasil, defendem um movimento de difusão e reaplicação dessas técnicas, metodologias e processos, pois entendem que estas se constituem em uma importante estratégia para o alcance da transformação social tão necessária para superação da situação de pobreza e para a instauração de uma ciência e tecnologia que esteja a serviço da construção de uma sociedade mais justa e igualitária. (FERNANDES e ACCORSSI, 2013, p. 196)

Podemos perceber a linha tênue existente entre as ações inovadoras, emancipatórias e de empoderamento das comunidades e a lógica de produção capitalista. Os interesses que podem muitas vezes ser conflitantes, às vezes podem convergir nos interesses dos detentores do poder hegemônico, e a conquistas de cidadania através do desen- 
volvimento de produtos tecnológicos sociais em mercadorias que podem e devem segundo a lógica do mercador serem comercializadas.

De acordo com Marx (1996, p.) "poder-se-ia escrever toda a história dos inventos que, a partir de 1830, surgiram apenas como armas do capital contra os motins operários", esta referência nos remete ao entendimento de que o processo inovador proposto pelo capitalismo não tem o objetivo apenas de acumular capital, mas também de controle do processo produtivo - substituindo o trabalhador por máquinas, evitando problemas sindicais, de certa forma inculcando nos trabalhadores um medo - e a reforçar seu poder.

A posse das tecnologias sempre, ao longo da história, garantiu a dominação econômica, militar e política sobre as nações e na contemporaneidade desempenha um papel central na dominação capitalista. É a tecnologia e sua posse que garante ao capitalista seu lugar de destaque ao gozar dos privilégios dentro da pirâmide socioeconômica, além é claro da influência política na sociedade capitalista.

Neste sentido, salientamos que não se pode combater a pobreza sem que haja por parte dos sujeitos o pleno entendimento de sua função no processo de construção social, e retirar de sua consciência a percepção de si mesmo como o "pobre", e desenvolver a ideia de sujeito, transformador de sua realidade, conforme Damo (2003, p. 38) destaca dizendo "antes de tudo é preciso conseguir que o pobre faça e se faça oportunidade, alçando-se a sujeito de sua própria história, sabendo ler criticamente sua condição social".

Para além da tomada de consciência da classe trabalhadora da importância das tecnologias sociais para seu empoderamento, é necessário que políticas públicas sejam formuladas para amparar estes trabalhadores e suas ideias.

\section{MODELOS DE TECNOLOGIAS SOCIAIS APLICADO À AGROECOLOGIA}

Um dos significados da agroecologia como ciência é a inter, multi e transdisciplinaridade, respeitando os saberes tradicionais, e 
garante que a técnica, processos e tecnologia sejam aplicadas na mesma comunidade desenvolvida privilegia desta forma o caráter territorial e particular de cada povoado. Isto quer dizer que a agroecologia como tecnologia sempre será desenvolvida com a finalidade de atender uma comunidade, e isso significa que nem sempre atenderá necessariamente de outras comunidades, uma vez que o objetivo é prestigiar e oferecer soluções para as necessidades locais.

Uma das propostas é a utilização correta do solo, com a finalidade de preservar ou recuperar áreas degradadas. De acordo com Mazoyer e Marcel (2010), o policultivo é um dos métodos mais antigos de agricultura, adotado no período neolítico quando a sociedade começa a se organizar, e as práticas agrícolas necessitam de desenvolvimento tecnológico para suprir a demanda da população.

A adoção deste modelo onde é possível, garante a maximização da utilização do solo, sem oferecer a estes muitos riscos, como define Liebman (2012, p. 221),

Os policultivos podem envolver combinações de espécies anuais com outras anuais, anuais com perenes, perenes com perenes. Os cereais podem ser consorciados com leguminosas ou raízes e tuberosas podem ser consorciadas com árvores frutíferas. Ao politicultivos podem apresentar diversos arranjos espaciais, desde uma simples combinação de duas espécies em fileiras alternadas, até consórcios complexos de mais de uma dúzia de espécies misturadas. As culturas componentes dos consórcios podem ser plantadas na mesma época, ou em épocas diferentes (culturas sequenciais); as colheitas também podem ser simultâneas escalonadas.

O uso dos consórcios de policultivo garantem aos agricultores a máxima utilização da terra em suas dinâmicas espaciais, isso porque em geral, estes agricultores possuem uma fração de terra limitada, exigindo destes que se utilize da melhor forma do seu pequeno roçado. Para além disso, ainda permite o controle de pragas e de ervas daninhas com maior eficiência. 
Através disso podemos salientar nas palavras de Oliveira et. al. (2015, p. 4) que no sistema de policultivo,

[...] constata-se que a diversificação da produção agrícola numa pequena área de cultivo, além de alimentar e gerar trabalho à família, gera também renda e qualidade de vida. Evidencia-se que a biodiversidade deste sistema complexo de cultivo, da forma como está sendo manejada pelo agricultor, possibilita o sucesso na convivência com as adversidades daquele ambiente. Insetos e doenças quando incidem nas culturas não causam perdas tão significativas ao ponto de comprometer a produção agrícola.

Neste modelo cada espécie tem sua função, e em conjunto garantem a resistência da terra e da plantação, sustenta ainda a resiliência de áreas degradadas, isto tudo privilegia a efetivação da agroecologia como sistema produtivo ambiental, social e economicamente sustentável.

Também sustentável é o modo de produção por meio da cobertura do solo com plantas herbáceas, anuais ou perenes, de forma solteiras ou consorciadas, que tem a função de proteger o solo em determinada época, ou durante o ano. Isto garante a proteção do solo contra a erosão, melhora a condição do solo e sua fertilidade, inibe o aparecimento de pragas e o aparecimento de plantas daninhas.

O cultivo de cobertura para o solo oferece importantes benefícios tais como a melhoria na penetração da água e a sustentação da umidade em períodos quentes, possibilita que a terra não fique compactada devido as chuvas, uma vez que a cobertura serve como almofada e reduz o impacto das gotas ao solo, e então a formação de crostas. Possibilita que receba ar do ambiente com maior facilidade. Com a cobertura o solo não escorre para vala com as chuvas que tendem a lavar a superfície descoberta.

A decomposição da matéria orgânica garante ao solo maior disposição para a absorção de nutrientes através da afixação do nitrogênio². Auxilia no abrigo de insetos predadores de parasitas,

2 O nitrogênio $(\mathrm{N})$ é o nutriente responsável para o crescimento das plantas, para a produção de novas células e tecidos. O nitrogênio promove a formação de clorofila, que 
e abriga parasitas benéficos. Ainda modifica o microclima do solo, sua temperatura, umidade tornando assim mais as condições físicas para o crescimento das plantas.

A cobertura do solo pode ser feita por exemplo, com milheto, sorgo, cevada, entre outros, podendo estes serem colhidos e seus dejetos também serem utilizados como ração animal. Nas culturas de pomares, a utilização da cobertura pode se dar através do cultivo de frutas rasteiras como melancia, melão, bem como de vegetais rasteiros como abóbora, pepino, maxixe, entre outros, possibilita desta forma ao agricultor variar sua produção e proteger o solo.

Altieri (2012, p. 255) corrobora com esta afirmação dizendo que "o uso de leguminosas em rotação de culturas ou como adubo verde é muito útil no controle da erosão e na manutenção da matéria orgânica do solo". Este modelo se mostra muito vantajoso para os produtores pois garante a diversificação da produção, impede o escorrimento da superfície do solo, reduz a consideravelmente a erosão. Bastante similar ao modelo de cobertura do solo, a rotação de cultura, que de acordo com Summer (1982),

[...] evidências indicam que as rotações influenciam a produção vegetal, ao afetar a fertilidade do solo, a sobrevivência dos patógenos, as propriedades físicas do solo, a erosão do solo, a microbiologia do solo, a sobrevivência dos nematoides insetos, ácaros, vegetação espontânea, minhocas e fitotoxinas.

Basicamente a rotação de cultura consiste em que as espécies diferentes são plantadas de forma alternada em uma mesma área, podendo ou não serem repetidas. Este modelo necessita respeitar alguns princípios como sempre incluir leguminosas, manter a fertilidade do solo equilibrada com exploração agrícola eficiente, evitar espécies que possam ter a mesma vulnerabilidade da mesma praga ou doenças, usar adubação ecológica, aumentar o teor de matéria orgânica no solo.

é um pigmento verde encontrado nas folhas e que captura a energia do sol. A clorofila combina $\mathrm{CO} 2+\mathrm{H} 2 \mathrm{O}$ formando açúcares, que a planta necessita para o seu crescimento e produção de grãos e frutos. (BRAGA, 2010) 
Os objetivos da rotação de culturas são: incorporar diversidade no sistema agrícola, fornece nutrientes às culturas e controlar pragas. Os mecanismos que atuam nas interações planta/ animal, desenvolvidos a partir das rotações de culturas, numa propriedade agrícola, determinam o que se pode chamar de estrutura biológica de um agroecossistema. (Altieri, 2012, p. 262).

No Brasil, em alguns Estados, existe a adoção do vazio sanitário, que consiste no descanso da terra depois de um período sucessivo de cultivo extensivo da monocultura básica, principalmente em áreas dominadas pela soja, feijão e algodão. Não é a mesma coisa, mas a base é a mesma. A rotação de culturas tem a mesma finalidade do vazio sanitário, porém com a possibilidade de plantar outras culturas.

Podemos salientar ainda como método de produção pelo Sistemas Agroflorestais (SAF), que consiste em cultivo de árvores em consórcio direto com outras vegetações rasteiras. Este consórcio pode também ser utilizado com a produção animal podendo ser de maneira simultânea ou sazonal.

Sistema agroflorestal é um nome genérico que se utiliza para descrever sistemas tradicionais de uso da terra amplamente utilizados, nos quais as árvores são associadas no espaço e/ou no tempo com espécies agrícolas anuais e/ou animais. Combina-se, na mesma área, elementos agrícolas com elementos florestais, em sistemas de produção sustentáveis. (FARRELL; ALTIERI 2012, p. 281)

Os sistemas agroflorestais têm como objetivo otimizar os resultados positivos da interação entre espécies arbóreas, com as demais culturas utilizadas pelo produtor, bem como a criação de animais no mesmo espaço. É com o objetivo de obter os resultados semelhantes do modelo de monocultura, com produção comparáveis pelas dadas as condições econômicas, sociais e ecológicas (NAIR, 1983).

Para além destes modelos e técnicas utilizados no processo produtivo, outras tecnologias sociais são encontradas, muitos deles a partir da criatividade do sertanejo e das populações tradicionais, 
que encontram em sua vida simples maneiras de tornar a vida no campo mais fácil.

Um dos exemplos mais contundentes é o uso de cisternas para o combate à seca e o acesso a água potável pelos trabalhadores rurais, principalmente na região do Nordeste brasileiro onde ano após ano as comunidades sofriam com a falta de água. Esta situação acarretava na perda de lavouras e de animais, o que acentuava a pobreza e a miséria nestas localidades.

O Programa Um Milhão de Cisternas surgiu em 2003, no primeiro ano do governo do Presidente Luiz Inácio Lula da Silva através do Ministério de Desenvolvimento Social em parceria com a $\mathrm{ASA}^{3} \mathrm{com}$ o objetivo de sanar problemas de acesso a água da população que habitava a região do Semiárido nordestino.

A cisterna constitui uma tecnologia simples e de fácil reaplicação, sendo estas algumas das características que explicam sua rápida disseminação pelo Semiárido. A cisterna padrão é uma construção circular com raio de cerca de $2 \mathrm{~m}$ construída sobre um buraco de 1,2 $\mathrm{m}$ de profundidade (podendo variar em função do terreno), com capacidade para armazenar até 16 mil litros de água. (COSTA; SILVA, 2013, p. 52)

Geralmente são construídas próximas às casas com tubulação conectada ao telhado da casa para que a água da chuva seja coletada, sendo que a primeira chuva, deve ser usada para a limpeza da tubulação e desta forma é necessário descartar esta água. As demais chuvas fornecem água que são armazenadas na cisterna para a utilização nos meses de estiagem. O Ministério do Desenvolvimento Social des-

3 A ASA é uma rede que defende, propaga e põe em prática, inclusive através de políticas públicas, o projeto político da convivência com o Semiárido. É uma rede porque é formada por mais de três mil organizações da sociedade civil de distintas naturezas - sindicatos rurais, associações de agricultores e agricultoras, cooperativas, ONG's, Oscip, etc. Essa rede conecta pessoas organizadas em entidades que atuam em todo o Semiárido defendendo os direitos dos povos e comunidades da região. As entidades que integram a ASA estão organizadas em fóruns e redes nos 10 estados que compõem o Semiárido Brasileiro (MG, BA, SE, AL, PE, PB, RN, CE, PI e MA) (Disponível em: <http://www. asabrasil.org.br/>. Acesso em: março de 2017). 
taca que as capacidades das cisternas são suficientes para suprir as necessidades de água de uma família de cinco pessoas por cerca de 8 meses, com o consumo moderado da água (BRASIL, 2016).

. Esta moderação é alcançada mediante ações de conscientização realizada pela ASA e por demais organizações da sociedade civil que estão envolvidas neste projeto.

Anterior ao Programa Um Milhão de Cisternas os trabalhadores rurais já se mobilizavam através do Fundo Rotativo Solidário, que também compõe a gama de tecnologias sociais. Esta iniciativa nada mais é do que uma poupança criada por doações voluntárias dos membros das comunidades ou incentivos externos, através de ONGs, sociedade civil, organizações internacionais, governo, etc.

Os chamados Fundos Rotativos Solidários (FRS), enquanto mecanismos de mobilização e valorização social da poupança comunitária, assumem a forma de gestão compartilhada de recursos coletivos. São constituídos a partir da contribuição das famílias ou estimulados por um capital externo, que pode proceder de diversas fontes. Têm sido, na verdade, um exercício fundamental na busca da sustentabilidade dos sistemas familiares, na perspectiva da convivência com a região semi-árida e na transição agroecológica. (ROCHA; COSTA, 2005, p. 13)

Apesar da conceituação dos Fundos Rotativos Solidários serem claros, os arranjos podem se dar de diversas formas, respeitando sempre as particularidades de cada comunidade, e as necessidades que cada uma apresenta. Estas necessidades se manifestam de diferentes maneiras, e os fundos podem se formar para suprir a necessidade de sementes com os bancos de sementes, a criação de animais, construção de barragens, açudes, canteiros, cisternas, armazéns, e na compra de equipamentos e maquinários, como telas, fornalhas ecológicas, etc.

Uma das grandes características, como em todas as tecnologias sociais, é o envolvimento das famílias. Esta participação social, garante a efetividade e concretude dos projetos, e neste sentido Bronzeado et. al. (2012, p. 7) destaca que: 
[...] a dinâmica dos FRS se configura como um poderoso instrumento de mobilização, envolvimento e capacitação das famílias, atuando principalmente em relação à autonomia da comunidade sobre os bens dos quais, historicamente, elas eram dependentes de água, sementes. Os FRS são também espaços de conhecimento onde a comunidade aprende a fazer a gestão dos recursos e o planejamento das atividades inseridas numa perspectiva solidária.

Não cabe dúvidas quanto a consideração da FRS como tecnologia social, uma vez que é uma resposta contra hegemônica ao modelo vigente, que necessita da interação com a sociedade e busca soluções efetivas para problemas sociais estruturais, além de propor transformação econômica, social e ambiental aos envolvidos. Estas relações sociais buscam uma sociedade mais justa, equitativa e inclusiva, sempre com responsabilidade socioambiental.

\section{O NORDESTE BRASILEIRO: O SEMIÁRIDO COMO ESPAÇO ECONÔMICO-SOCIAL}

Tendo como característica básica o déficit hídrico e com grande incidência de energia solar as regiões semiáridas do planeta compõe percentual elevado de extensão territorial no Brasil e oferecem ainda condições adversas como solo raso, alta evaporação devido à retirada da cobertura vegetal e da exploração incorreta dos recursos naturais. Desta forma, o semiárido brasileiro demonstra ser uma região única e especial no planeta, com características edafoclimáticas, biótico, econômico e sociais próprias.

No âmbito do Brasil, o Semi-árido abrange $70 \%$ da área do Nordeste, mais o norte de Minas Gerais. A região é coberta por solos rasos de baixa fertilidade e caracterizada pela vegetação da Caatinga. Os problemas básicos dessa região são a escassez e a irregularidade de chuvas. Ciclicamente ocorrem estiagens prolongadas, com reflexos danosos 
na economia e com custos sociais elevados. (CÂNDIDO, ARAÚJO e CAVALCANTE, p. 1, 2012).

De acordo com o Ministério da Integração (MI) (2005) a extensão da área classificada como semiárido brasileiro, é de $969.590 \mathrm{~km} 2,70 \%$ do Nordeste do Brasil, e sendo possuidor de uma população de cerca de 23 milhões de habitantes, o que corresponde a $11 \%$ da população brasileira (IBGE, 2014).

O clima é favorável à agricultura, porém a imprevisibilidade das estações chuvosas é um problema decorrente de tal forma que há épocas em que são elevados os índices pluviométricos em curto espaço de tempo, ou seja, a chuva precipita de forma demasiada em um curto espaço de tempo. Em contraposição há épocas com longo períodos de seca com altas temperaturas e radiação solar, e os aportes de nutrientes nos ecossistemas semiáridos são relativamente constantes durante $o$ ano.

Climaticamente, o semi-árido brasileiro caracteriza-se por clima quente e seco, com duas estações, a seca e a úmida, com pluviosidade situada nas isoietas de, aproximadamente, 300-800 $\mathrm{mm}$. A maior parte das chuvas se concentra em três a quatro meses dentro da estação da úmida, acarretando um balanço hídrico negativo na maioria dos meses do ano e elevado índice de aridez. (CÂNDIDO, ARAÚJO e CAVALCANTE, p. 2, 2012).

O solo característico da região são os sedimentos arenosos, mas em geral os solos do semiárido apresentam boas características físicas sendo aptos à agricultura, a maioria tem características químicas adequadas, sendo as principais dificuldades referentes à topografia, alta densidade de pedras, profundidade e drenagem. O bioma predominante é a Caatinga que tem por abrangência $900 \mathrm{mil} \mathrm{km}^{2}, 11 \%$ do território nacional, e cobre parte dos Estados do Ceará, Rio Grande do Norte, Pernambuco, Alagoas, Sergipe, o sudoeste do Piauí, partes da Bahia e do norte de Minas Gerais.

A caatinga pode ser descrita como uma vegetação espinhenta, de folhas pequenas e caducas, constituídas por arbustos e árvores de pe- 
queno porte, rica em cactáceas, bromeliáceas, euforbiáceas e leguminosas, conta ainda com forragem peculiar que se torna característico do bioma, além de contribuir na preservação da umidade do solo, mas ações antrópicas oriundas da exploração extrativista da população local, que desconhece qualquer técnica de boas práticas de cultivo, tem acarretado na rápida diminuição das coberturas naturais de espécies nativas, inclusive ameaçando-as de extinção.

O MI (2009) destaca que o semiárido consiste em uma das sub-regiões brasileiras e que necessita de maior intervenção por parte do Estado de forma eficiente para diminuir e eliminar os efeitos climáticos danosos que desestruturam e prejudicam o desenvolvimento local, neste sentido, a economia local do semiárido sofreu mudanças drásticas no decorrer do século $X X$, especialmente na segunda metade onde podemos verificar o aumento no volume de circulação de mercadorias e serviços produzidos na região, mas estas novas atividades econômicas não supriram o espaço vazio deixado pelo antigo modelo produtivo da região que era formado pela criação de gado, plantio de cana de açúcar, algodão e subsistência o que causou desestruturação do complexo econômico (MI, 2009).

A economia do semiárido é ligada a atividades rurais, como a criação de animais, cultivo de leguminosas, hortaliças, grãos e frutas, que por sua vez se associam a agroindústria que beneficia esta produção, e também é presente a indústria de bens, bem como os serviços.

A economia do semiárido mudou drasticamente desde a metade do século XX, verifica-se o crescimento no volume de mercadorias e serviços produzidos, no entanto estas novas atividades econômicas não foram suficientes para ocupar o espaço vazio deixado pela desconstrução do complexo econômico formado pela criação de gado, plantio de algodão e lavouras alimentares. (ALBIERI, p. 13, 2015)

Seguindo a perspectiva da produção de pequenas propriedades que tem por característica garantir a subsistências das famílias e promover a troca/venda dos excedentes nos mercados locais a agroecologia tem ganhado protagonismo, uma vez que oferece vantagens para os 
produtores ao possibilitar aos mesmos alimentos saudáveis que consequentemente agrega valor ao produto para a venda.

\subsection{Agroecologia na convivência com o semiárido}

A agroecologia surge como uma proposta que confronta a lógica produtivista do agronegócio privilegiando os saberes tradicionais, ainda propõe a transversalidade das ciências que se debruçam a estudar e melhorar os processos produtivos sustentáveis com o diálogo entre os vários campos da ciência (sociologia, filosofia, psicologia, agronomia, economia, administração, ecologia, física, química, etc.) com a finalidade de fortalecer este modelo produtivo levando sempre em consideração os saberes tradicionais.

Considerada como a ciência que aplica conceitos e princípios ecológicos para desenhar um agroecossistema sustentável, a agroecologia ultrapassa o uso de práticas alternativas e de sistemas produtivos com baixa incidência de produtos químicos e de utilização minimizada de energia, o que garante o equilíbrio ambiental da produção, reduzindo os danos ao bioma a qual está inserida.

A principal proposta da agroecologia é enfatizar a utilização dos agroecossistemas complexos garantido que a interação biológica e a sinergia dos compostos biológicos provoquem a criação de mecanismos para que o próprio sistema subsidiem a fertilização do solo, sua produtividade e a qualidade dos produtos, o que resulta em saúde para o ambiente, para quem consome os produtos e para quem vive neste espaço.

O conceito de "convivência com o semi-árido", desenvolvido em oposição ao conceito de "luta contra as secas", acabou mobilizando a sociedade civil e motivou a elaboração de referências tecnológicas e organizativas propostas para um novo modelo de políticas públicas, de longo prazo, estruturantes, que permitissem a convivência com o semi-árido, de tal forma que os socorros pudessem ser definitivamente dispensados. Esse novo modelo seria baseado no respeito à dignidade das populações antes consideradas como dependentes; agora, elas eram chamadas a se mobilizar para assumir de forma organizada e cria- 
tiva as soluções próprias a enfrentar os desafios do semi-árido. Seu saber tradicional e seus experimentos de manejo da natureza passaram a ser valorizados e aprimorados, no diálogo com o saber científico. (DUQUE, p. 136, p. 2008).

A ciência moderna propõe a transferência tecnológica verticalizada, ou seja, de cima para baixo, desprestigiando os saberes populares, o que ainda promove a cultura consumista, economicista de empresas ligadas ao agronegócio, motivando o monopólio produtivo no campo. Estas tecnologias não são adequadas para pequenos, médios produtores e camponeses empobrecidos pois os mesmos são excluídos do acesso ao crédito agrícola, à informação, ao apoio técnico e demais serviços que auxiliem a utilização e adaptação dos insumos vendidos pelas multinacionais, para que desta forma garantam a sua existência e permanência no campo.

O agronegócio é o retrato diminuído das atuais circunstâncias econômicas mundiais. Protegido por Estados que compactuam com o modelo econômico neoliberal, que promove o distanciamento entre os ricos e os pobres, privilegiando a concentração de renda e a exclusão social.

Nesse sentido o trabalho camponês se torna uma forma de resistência ao modelo imposto pelo agronegócio, ou seja, as populações locais, dentro de suas especificidades, possuem técnicas ao manejar o solo, as culturas e a criação de animais, produzidos para a autossuficiência/auto-consumo, valor de uso e não de troca, na diversificação dos sistemas produtivos, em oposição às monoculturas, explorando de forma eficiente os diferentes agroambientes, utilizando da heterogeneidade espacial e da diversidade biológica, utilizando mais de práticas de convivência do que de práticas de restrições ambientais, maior aproveitamento dos recursos locais, pelo baixo uso de insumos externos e pelo conjunto de conhecimentos de caráter holístico; a conservação da natureza não é algo separado das atividades produtivas - é fonte de sobrevivência - e também por preservar valores simbólico-religioso/tradicionais relacionados ao lugar. (GUIMARÃES E MESQUITA, p. 11, 2010) 
Para promover a produção dos agricultores empobrecidos, a pesquisa e o desenvolvimento agrícola deve abordar um saber cientifico horizontalizado e utilizar os recursos já disponíveis (população local, seus saberes e recursos naturais nativos). E ao dialogar com as comunidades envolvidas considerar a participação social, as necessidades das populações engajadas, aspirações e contextos em que os agricultores estão inseridos. Neste sentido, Duque destaca que:

Para que a convivência com o semi-árido seja sustentável do ponto de vista econômico, as tecnologias propostas têm que ser de baixo custo e de replicação fácil pelas famílias agricultoras da região. Para que seja sustentável do ponto de vista ambiental, essas tecnologias devem ser respeitosas do meio ambiente. Finalmente, para que haja convivência socialmente sustentável, essas mesmas tecnologias devem ser frutos de um processo pedagógico e político que aproveite o saber das famílias produtoras e dialogue com elas, permitindo-lhes apropriarem-se do mesmo e difundi-lo de forma autônoma, dispensando aos poucos a presença de mediadores. Portanto, fica claro que os aspectos organizativos e educativos estão intimamente interligados com os aspectos tecnológicos. (DUQUE, p. 137, 2008)

Esta construção social e tecnológica leva a criação de tecnologias que fogem dos padrões desenvolvimentistas da ciência moderna, antes prestigia o meio ambiente através de sua conservação, inibindo a utilização de insumos que possam destruir os ecossistemas.

\section{CONSIDERAÇÕES FINAIS}

O objetivo deste texto foi debater de que forma a agroecologia e as tecnologias podem contribuir para a convivência dos trabalhadores rurais nordestinos com o semiárido brasileiro.

Nesta perspectiva, os processos de degradação ambiental tão avançados devido às condições climáticas e principalmente pela utilização incorreta dos recursos naturais, estão sendo revertidas pela utilização de tecnologias sociais de caráter agroecológicos. O que garante ain- 
da a permanência dos agricultores no território, diminuindo a pobreza rural e o êxodo rural.

A utilização das cisternas, além de uma conquista políticas, garante aos trabalhadores água potável por meses. Esta é uma das mais importantes tecnologias criadas, uma vez que a água é fundamental para a sobrevivência neste território. Além de garantir água para o consumo doméstico, ainda propicia condições para a irrigação dos vegetais cultivados e sacia a sede dos animais criado.

Como tecnologia social agroecológica a cobertura do solo, a rotação de cultura e o consórcio de culturas estão muito presentes nos espaços produtivos do semiárido. Com treinamento e capacitação técnica, as famílias agriculturas puderam fazer a transição agroecológicas sem prejuízo de produção, e garantem que o solo permaneça úmido por mais tempo, o que facilita a fertilização do solo e o uso de consórcio animal com a agricultura garante que os dejetos dos animas sirvam de fertilizantes naturais.

No caso das famílias que optaram pela agroecologia a mais tempo, a renda familiar já se encontra estabelecida, com pontos de venda já estipulados, quando não na própria propriedade. Os produtos oferecidos são os mais diversos, pois este é um dos pontos principais da agroecologia, a diversificação da produção, uma vez que é pensando na alimentação da família em primeiro lugar e apenas o excedente é vendido nas ecofeiras, feiras agroecológicas ou na propriedade mesmo.

Nesta perspectivas, a contribuição das tecnologias sociais e da agroecologia ultrapassa a ideia apenas da renda, é emancipatória, uma vez que os agricultores produzem alimentos para seu próprio consumo, é ambientalmente responsável pois convive com as particularidades climáticas sem degradas os recursos naturais, buscando a convivência saudável com o semiárido, respeitando os limites impostos pela natureza, preservando os recursos ali existentes.

\section{REFERÊNCIAS BIBLIOGRÁFICAS}

ALBIERO, Daniel. Fundamentos de projetos de máquinas agroecológicas para o semiárido. In.: (Org.) ALBIERO, Daniel; CAJADO, 
Diana Mendes; FERNANDES, Ivana Leila Carvalho; MONTEIRO, Leonardo de Almeida; ESMERALDO, Gema Galgani Silveira Leite. TECNOLOGIA AGROECOLÓGICAS PARA O SEMIÁRIDO. Fortaleza, Edição do Autor, 2015.

ALTIERI, Miguel. Agroecologia: Bases científicas para uma agricultura sustentável. 3. Ed. São Paulo: AS-PTA, 2012.

BAVA, Silvio C. Tecnologia Social e desenvolvimento local. In. Fundação Banco do Brasil. (Org.) Tecnologia Social: uma estratégia para o desenvolvimento. Rio de Janeiro: FBB, 2004. P. 103-116.

BRAGA, Gastão Ney Monte. A função do Nitrogênio para as Plantas. Disponível em: http://agronomiacomgismonti.blogspot.pt/2010/04/ as-funcoes-do-nitrogenio-para-as.html

BRASIL. Ministério do Desenvolvimento Social. Disponível em: http:// mds.gov.br/area-de-imprensa/noticias/2016/maio/programa-cisternasdemocratiza-agua-e-garante-convivencia-no-semiarido. Acesso: março de 2017.

CÂNDIDO, M. J. D.; ARAÚJO, G. G. L.; CAVAlCANTE, M. A. B. Pastagens no ecossistema semiárido brasileiro: atualização e perspectivas futuras. Disponível em: http://www.neef.ufc.br/pal05. pdf. Acesso em 12 de setembro de 2016.

COUTINHO, Carlos Nelson. Notas sobre cidadania. In. Revista Ágora: Políticas públicas e serviço social. Ano 2. Dezembro de 2005.

COSTA, B. Adriano; DIAS, Rafael de B. Estado e sociedade civil na implantação de políticas de cisternas. In. COSTA, B. Adriano (Org.). Tecnologia social e políticas públicas. São Paulo: Instituto Pólis; Brasília: Fundação Banco do Brasil, 2013.

DAGNINO, Renato; BRANDÃO, Flávio Cruvinel; NOVAES, Henrique Tahan. Sobre o marco analítico-conceitual da tecnologia social. Disponível em: http://www.mom.arq.ufmg.br/mom/18 ref_capes/ arquivos/arquivo 110.pdf 
DAGNINO, Renato. A Tecnologia Social e seus desafios. Tecnologia Social: uma estratégia para o desenvolvimento. Rio de Janeiro: FBB, 2004.

DAMO, Pedro. Pobreza da Pobreza. Rio de Janeiro: Vozes, 2003.

DUQUE, Ghislaine. "Conviver com a seca": contribuição da Articulação do Semi-Árido/ASA para o desenvolvimento sustentável. In.: Desenvolvimento e Meio Ambiente, n. 17. Editora UFPR, jan./jun. 2008, p. 133-140.

FARRELL, John G.; ALTIERI, Miguel A. Sistemas Agroflorestais. In. ALTIERI, Miguel A. Agroecologia: bases científicas para uma agricultura sustentável. 3. Ed. São Paulo: AS-PTA, 2012.

FERNANDES, Rosa Maria Castilhos. ACCORSSI, Aline. Pobreza e tecnologia social: o que isto tem a ver? In. Revista Lugar Comum. $\mathrm{N}^{\circ}$ 40. Uninomade Brasil, 2013.

GRAMSCI, Antônio. Os intelectuais e a Educação. Org. COUTINHO, Carlos Nelson. O leitor de Gramsci: Escritos escolhidos. Rio de Janeiro, Civilização Brasileira, 2011.

GUIMARÃES, R. R.; MESQUITA, H. A. de. Agroecologia e agronegócio: crises e convivências. In.: Espaço em Revista, $n^{\circ}$ 02, vol. 12. Catalão - GO, UFG-CAC, jul/dez. 2010, p. 1-17.

HERRERA, Amilcar (Org.). América Latina: ciência y tecnologia em el desarrollo de la sociedad. Santiago de Chile: Ed. Universitária, 1970. Capítulo: Notas sobre la ciência la tecnologia en el desarrollo de la sociedad.

ITS - INSTITUTO DE TECNOLOGIA SOCIAL. Reflexões sobre a construção do conceito de tecnologia social. In. Fundação Banco do Brasil. (Org.) Tecnologia Social: uma estratégia para o desenvolvimento. Rio de Janeiro: FBB, 2004.

LEFF, Enrique. Saber Ambiental: Sustentabilidade, racionalidade, complexidade e poder. Tradução: Lúcia Mathilde Endlich Orth. 10. Ed. - Petrópolis, RJ: Vozes, 2013. 
LIEBMAN, Matt. Sistemas de Policultivos. In.: ALTIERI, Miguel. Agroecologia: Bases científicas para uma agricultura sustentável. 3 . Ed. Rev. E Ampl. São Paulo: Expressão Popular; AS-PTA, 2012.

MARX, Karl. O Capital. Volume I. São Paulo: Nova Cultura, 1996.

MAZOYER M.; ROUDART L. História das agriculturas no mundo: do neolítico à crise contemporânea. Tradução de Cláudia F. Falluh Balduino Ferreira. São Paulo: Editora UNESP; Brasília, DF: NEAD, 2010.

NAIR, P. K. R. Tree integration on farmlands for sustained productivity of small holdings. In. LOCKERETZ, W, (ed.). Environmentally Sound Agriculture. New York: Praeger, 1983. P. 333-350.

OLIVEIRA, Maxwell da Rosa; SILVA, Elizabeth Sales da; SANTOS, Karine Aparecida Silva dos; FEIDEN, Alberto; BORSATO, Aurélio Vinicius. Policultivo como Prática de Transição Agroecológica no Assentamento 72, Ladario-MS. In. Cadernos de Agroecologia - Vol $10, N^{\circ} 3$ de 2015.

PYARELAL. Towards New Horizons. Ahmedabad: Navjivan Press, 1959.

RICHARDS, P. Indigenous agricultural revolution. Boulder, CO: Westview Press, 1985.

RODRIGUES, Ivete; BARBIERI, José Carlos; IWATA, Luís Fumio. A emergência da tecnologia social: Revisando o movimento da tecnologia apropriada como estratégia de desenvolvimento sustentável. In. XI Seminário Latino-Iberoamericano de Gestión Tecnológica. Salvador, 2005.

ROCHA, José C.; COSTA, José Waldir S. Fundo rotativo solidário: instrumento de promoção da agricultura familiar e do desenvolvimento sustentável no Semiárido. Revista Agriculturas. Vol. 2, n 3, out. 2005.

SANTOS, Boaventura de Sousa. A gramática do tempo: para uma nova cultura política. 2. Ed. Porto: Edições Afrontamento, 2010. 
SANTOS, Boaventura de Sousa. Para além do pensamento abissal: Das linhas globais a uma ecologia de saberes. Org. SANTOS, Boaventura de Sousa; MENESES, Maria Paula. Epistemologias do Sul. 2. Ed. Coimbra: Edições Almedina, 2010.

SEIXAS, Aline Silva; LIMA, Thaisi Leal Mesquita de; LIMA, Gabriel Maciel de; DANTAS, Thomas Kefas de Souza; GUIMARÃES, Patrícia Borba Vilar. As Tecnologias Sociais como instrumento para o desenvolvimento nacional. In. Revista GEINTEC. Volume 5, nº 4. São Cristóvão/SE. 2015.

SHIVA, Vandana. A violência da Revolução Verde: Agricultura, Ecologia e Política do Terceiro Mundo. Tradução: Luís Humberto Teixeira. Lisboa: Edições Mahatma, 2015.

SUMNER, D. R. Crop rotation and plant productivity. In. RECHEIGL, M. (Ed.) CRC handbook of agricultural productivity. v. I, Flórida: CRC Press, 1982.

http://www.asabrasil.org.br/. Acesso em: abril de 2018. 